\title{
A Certificação de Entidades de Assistência Social na área da saúde: alterações normativas 2008-2016
}

The Social Assistance Entities Certification in healthcare: legislative changes 2008-2016

La Certificación de Entidades de Asistencia Social en Salud: cambios normativos 20082016

\author{
Yegor Moreira Júnior ${ }^{1}$ \\ Sandra Mara Campos Alves ${ }^{2}$ \\ Lourdes Lemos Almeida ${ }^{3}$
}

RESUMO: A contratualização de estabelecimentos de saúde pelos gestores públicos é uma realidade em todo território nacional para complementar a rede pública na efetivação do direito constitucional à saúde. O presente artigo teve como escopo realizar levantamento das alterações legislativas ocorridas entre o período de 2008 a 2016 para concessão e renovação do Certificado de Entidades Beneficentes de Assistência Social na área da saúde-CEBAS-SAÚDE. O estudo tem natureza descritiva e analítica, a partir da pesquisa normativa. Dos nove atos normativos que tratam sobre o assunto, verificou-se modificações significativas quanto aos legitimados para obtenção do CEBAS-SAÚDE, à competência para certificar as entidades postulantes, ao prazo de validade e do pedido de renovação e as alternativas para não prestação de 60 \% dos serviços de saúde ao Sistema Único de Saúde-SUS. Conclui-se que houve alterações favoráveis às entidades beneficentes da área da saúde, mas isso não significa necessariamente incremento à rede pública de saúde.

Palavras-chave: Contratualização de Serviços de Saúde. Certificação de Entidades Beneficentes de Assistência Social em Saúde. Direito à Saúde.

ABSTRACT: The hiring of healthcare companies by public managers is a reality throughout the country to complement the public health system net in the realization of the constitutional right to health. This article was scoped to carry out a survey of legislative changes between the period 2008 to 2016 for concession and renewal of the Social Welfare Charitable Entities Certificate in Health-CEBAS-SAÚDE. The study has descriptive and analytical nature, from the legislative research. From 9 legal acts that deal with the subject, there has been significant changes as to legitimized to obtain the CEBAS-SAÚDE, the competence to certify candidates entities, the expiration date and the renewal application and the alternatives for not providing $60 \%$ of health services to the SUS Health-

\footnotetext{
${ }^{1}$ Mestre em Ciências-Jurídicas Internacionais pela Universidade de Lisboa, reconhecido pela Universidade Federal de Goiás-UFG, consultor da Organização Pan-Americana de Saúde-OPAS junto à Consultoria Jurídica do Ministério da Saúde, advogado e professor universitário na faculdade CECAP. Brasília - Distrito Federal. Brasil E-mail:yegormoreira@hotmail.com

${ }_{2}$ Pesquisadora colaboradora e docente do Programa de Direito Sanitário da Fiocruz Brasília. Doutoranda em Saúde Coletiva, UnB; mestre em Política Social. Brasília - Distrito Federal. Brasil. E-mail: smcalves@gmail.com

${ }^{3}$ Mestre em Saúde Coletiva pela Universidade de Brasília. Gerente do Núcleo de Gestão e Planejamento do Conselho Nacional de Secretários de Saúde - Conass. Brasília - Distrito Federal. Brasil. E-mail: lourdes.almeida@conass.org.br
} 
System. It follows an amendment favorable to the charitable health organizations, but that does not necessarily mean increasing and improvement the public health system and must to be analysed and discussed.

Keywords: Contracting health services. Certification Charities of Social Assistance in Health. Right to Health.

RESUMEN: La contratación de los servicios de salud por los administradores públicos es una realidad en todo el país para complementar el público en el ejercicio del derecho constitucional a la salud. Este artículo fue con ámbito para llevar a cabo un estudio de los cambios legislativos entre el período de 2008 a 2016 para la concesión y renovación del Certificado de Entidades de Bienestar Social en salud-CEBAS-SALUD. El estudio es la naturaleza descriptiva y analítica, de la investigación normativa. A partir de nueve actos normativos que tienen que ver con el tema, ha habido cambios significativos en cuanto a legitimado para obtener el CEBAS-SALUD, la competencia para certificar candidatos entidades, la fecha de vencimiento y la solicitud de renovación y las alternativas para no proporcionar $60 \%$ de los servicios de salud a la Salud-Sistema SUS. De ello se desprende una modificación favorable para las organizaciones de salud de caridad, pero eso no significa necesariamente un incremento el aumento de la salud pública.

Palabras-Ilave: La Contratación de Servicios de Salud. Certificación de Organizaciones Benéficas de la Asistencia Social en Salud. Derecho a la Salud.

\section{Introdução}

A relação entre o setor privado e o Estado na prestação de serviços públicos de saúde não é recente e tem sido cada vez mais intensa.

Com fundamento no parágrafo primeiro do artigo 199 da Constituição Federal - CF de 1988 e no artigo 24 da Lei oㅜ 8.080, de 19 de setembro de 1990, a participação complementar no Sistema Único de Saúde - SUS, é possível quando as disponibilidades de oferta de serviços na rede pública de saúde são insuficientes para garantir a cobertura assistencial à população de uma determinada área. Diante disso, o gestor estadual ou municipal pode complementar a oferta dando a devida preferência às entidades filantrópicas e sem fins lucrativos, e no caso de persistir a necessidade de complementação é permitido recorrer à iniciativa privada, observado o disposto na Lei no 8.666, de 1993 para a contratualização. Estima-se que pelo menos $89 \%$ dos estabelecimentos privados de saúde prestam serviços ao SUS (1).

Dados revelam que atualmente, a rede hospitalar beneficente é responsável por $37,98 \%$ dos leitos disponíveis no SUS, distribuídos em 6,3 mil estabelecimentos em todo o Brasil. Desse total, 1,7 mil são hospitais beneficentes que prestam serviços ao SUS e 
aproximadamente mil são os municípios cuja assistência hospitalar é formada somente por Santas Casas e Hospitais Filantrópicos. (2) (3)

Para atrair essas entidades, o Estado utiliza incentivos financeiros e tributários como a isenção de contribuições para a seguridade social prevista no texto constitucional alínea c do inciso VI do artigo 150 e $\$ 7^{\circ}$ do artigo 195, e o Programa de Reestruturação e Contratualização dos Hospitais Filantrópicos Sistema Único de Saúde, que destina repasse de recursos financeiros às entidades contratadas. Estima-se que a renúncia fiscal ou gastos tributários ${ }^{4}$ de contribuição previdenciária devida as entidades filantrópicas, no ano de 2015 , girou em torno de $R \$ 10$ bilhões. Insta lembrar que ao deixar de arrecadar parte dos tributos, o Estado age como se estivesse realizando um pagamento. (4) (5).

O principal requisito para a entidade sem fins lucrativos em saúde ter acesso a esses incentivos é a obtenção da Certificação de Entidade Beneficente de Assistência Social CEBAS. Antes concedido exclusivamente pelo Conselho Nacional de Assistência Social, do Ministério de Desenvolvimento Social e Combate à Fome, a partir da Medida ProvisóriaMP oㅜ 446, de 07 de novembro de 2008, passou a ser conferido também pelos Ministérios da Saúde e da Educação, ficando cada setor responsável pela certificação na sua área. O Ministério da Saúde, por meio da Secretaria de Atenção à Saúde, é responsável pela condução do processo de concessão ou renovação da Certificação de Entidades Beneficentes de Assistência Social na área da saúde, CEBAS-SAÚDE (6).

Dessa forma, as entidades reconhecidas como beneficentes de assistência social, pessoas jurídicas de direito privado, e sem fins lucrativos, que têm a finalidade de prestação de serviços nas áreas de assistência social, saúde ou educação, conforme o artigo 1ํ da Lei no 12.101 e que participam do SUS em caráter complementar, são objeto do nosso estudo. (7)

No período de 2008 a 2016 houve uma proliferação normativa considerável sobre o tema (Quadro 1), o que despertou interesse em proceder investigação com o objetivo de verificar as principais alterações normativas no que concerne aos requisitos para

4 Gastos tributários são gastos indiretos do governo realizados por intermédio do sistema tributário, visando atender objetivos econômicos e sociais. São explicitados na norma que referencia o tributo, constituindo-se uma exceção ao sistema tributário de referência, reduzindo a arrecadação potencial e, consequentemente, aumentando a disponibilidade econômica do contribuinte. Têm caráter compensatório, quando o governo não atende adequadamente a população dos serviços de sua responsabilidade, ou têm caráter incentivador, quando o governo tem a intenção de desenvolver determinado setor ou região. 
concessão e renovação do CEBAS-SAÚDE, notadamente na identificação (i) dos legitimados para obtenção da certificação; (ii) do órgão julgador responsável pelo processo; (iii) do prazo de validade do CEBAS-SAÚDE; (iv) do prazo para o pedido de renovação da certificação e (v) percentual de oferta de serviços ao SUS.

Quadro 1 - Normas editadas entre 2008 e 2016 sobre Certificação de Entidades Beneficentes de Assistência Social

\begin{tabular}{|c|c|}
\hline Data & Norma \\
\hline 7 de novembro de 2008 & MP no 446 \\
\hline 27 de novembro de 2009 & Lei $\mathrm{n}^{\circ} 12.101$ \\
\hline 11 de junho de 2010 & Lei no 12.249 \\
\hline 14 de setembro de 2010 & Decreto $\mathrm{n}^{\circ} 7.300$ \\
\hline 20 de julho de 2010 & Decreto $\mathrm{n}^{\circ} 7.237$ \\
\hline 04 de novembro de 2010 & Portaria/GM/MS no 3.355 \\
\hline 21 de julho de 2011 & Lei no 12.453 \\
\hline 16 de agosto de 2011 & Portaria/GM/MS no 1.970 \\
\hline 18 de julho de 2012 & Lei no 12.688 \\
\hline 15 de outubro de 2013 & Lei no 12.868 \\
\hline 23 de maio de 2014 & Decreto $\mathrm{n}=8.242$ \\
\hline 13 de novembro de 2014 & Lei no 13.043 \\
\hline 28 de julho de 2015 & Lei n 13.151 \\
\hline 14 de dezembro de 2015 & Lei no 13.204 \\
\hline 26 de abril de 2016 & Portaria/GM/MS 834 \\
\hline
\end{tabular}

Fonte: www.planalto.gov.br

O recorte temporal da pesquisa iniciou-se com a Operação Fariseu, deflagrada pela Policia Federal para investigar o esquema de fraude na concessão da certificação de entidades beneficentes no Conselho Nacional de Assistência Social-CNAS, em 2008 ${ }^{5}$, e que teve como consequência, a edição, da MP no 446/08 para dispor sobre a certificação das entidades beneficentes de assistência social e sobre os procedimentos de isenção de contribuições para a seguridade social (8).

\footnotetext{
${ }^{5}$ Para maiores informações veja http://www.dpf.gov.br/agencia/estatisticas/operacoes/2008\#Fariseu.
} 


\section{Metodologia}

Foi realizado um estudo de caráter descritivo-analítico dos atos normativos referentes à certificação de entidades beneficentes de assistência social na área da saúde.

O levantamento da legislação que trata sobre o tema da renovação do CEBASSAÚDE, produzida no período de 2008 a 2016, foi realizado no site do Poder Executivo www.planalto.gov.br e do Poder Legislativo www.camara.gov.br. Foram compreendidas na pesquisa as seguintes espécies legislativas: medidas provisórias (MP), decretos (DEC), leis ordinárias (LO).

De forma complementar foram ainda pesquisados os sítios do Ministério da Saúde http://portal2.saude.gov.br/saudelegis, as portarias emitidas no período estudado, bem como as decisões judiciais sobre o tema, perante o Supremo Tribunal Federal (www.stf.jus.br).

A revisão bibliográfica que trata da contratualização de entidades privadas no SUS e renúncia fiscal no setor saúde foi condição inicial para o estudo e oferece a fundamentação teórica à análise empreendida, bem como o estudo específico da legislação do CEBAS no período entre 2008-2016.

\section{Resultados}

No levantamento dos atos normativos referente à Certificação de Entidades Beneficentes de Assistência Social na área da saúde, CEBAS-SAÚDE, no período de estudo foram encontrados 9 (nove) atos normativos, assim classificados: uma medida provisória, três leis ordinárias, dois decretos e três portarias do Ministério da Saúde (Quadro 2). 
Quadro 2 - Normas editadas entre 2008 e 2016, selecionadas para análise

\begin{tabular}{|c|c|}
\hline Data & Norma \\
\hline 7 de novembro de 2008 & MP no 446 \\
\hline 27 de novembro de 2009 & Lei $n^{\circ} 12.101$ \\
\hline 20 de julho de 2010 & Decreto $\mathrm{n}^{\circ} \mathrm{7.237}$ \\
\hline 04 de novembro de 2010 & Portaria/GM/MS no 3.355 \\
\hline 21 de julho de 2011 & Lei no 12.453 \\
\hline 16 de agosto de 2011 & Portaria/GM/MS no 1.970 \\
\hline 15 de outubro de 2013 & Lei no 12.868 \\
\hline 23 de maio de 2014 & Decreto $\mathrm{n}^{\circ} 8.242$ \\
\hline 26 de abril de 2016 & Portaria/GM/MS 834 \\
\hline
\end{tabular}

Fonte: www.planalto.gov.br

Insta esclarecer que o inciso IV do artigo 18 da Lei ำ 8.742, de 1993, que foi regulamentado pelo Decreto № 2.536, de 6 de abril de 1998, alterado pelo Decreto 3.504 de 13 de junho de 2000, serviu de paradigma para analisar a Lei ํㅜ 12.101, de 27 de novembro de 2009, já que entre esta lei e a MP oㅡ 446, de 2008, este arcabouço normativo retornou à sua vigência. (9) (10) (11).

O quadro 3 representa um resumo da análise das principais alterações normativas que foram objeto do estudo. 
Quadro 3. Principais alterações normativas referentes à concessão e renovação do CEBAS-SAÚDE, no período de 2008-2016.

\begin{tabular}{|c|c|c|c|c|c|c|c|c|c|}
\hline & MP n 4ㄷ/08 & Lei nº 12.101/09 & $\begin{array}{l}\text { Decreto } \\
7.237 / 10 \\
\end{array}$ & $\begin{array}{l}\text { Portaria } \\
3.355 / 10 \\
\end{array}$ & $\begin{array}{c}\text { Lei no } \\
12.453 / 11\end{array}$ & $\begin{array}{l}\text { Portaria } \\
1.970 / 11 \\
\end{array}$ & Lei no $12.868 / 13$ & $\begin{array}{l}\text { Decreto } \\
8.242 / 14 \\
\end{array}$ & $\begin{array}{c}\text { Portaria } \\
834 / 16 \\
\end{array}$ \\
\hline $\begin{array}{l}\text { Legitimados } \\
\text { para } \\
\text { obtenção do } \\
\text { CEBAS- } \\
\text { SAÚDE }\end{array}$ & 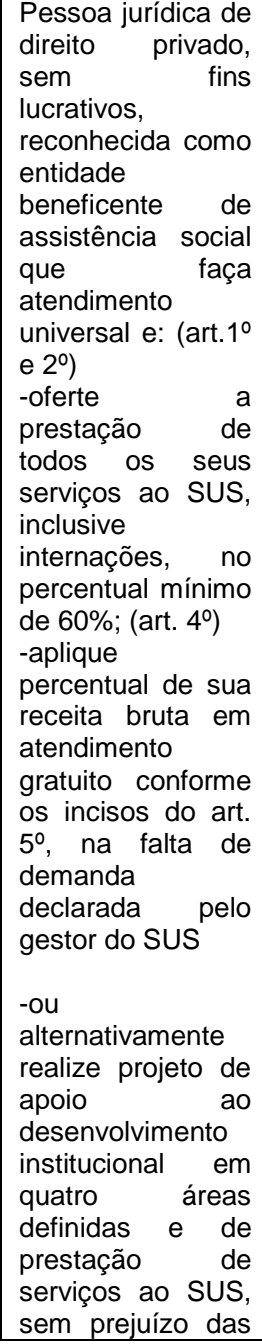 & 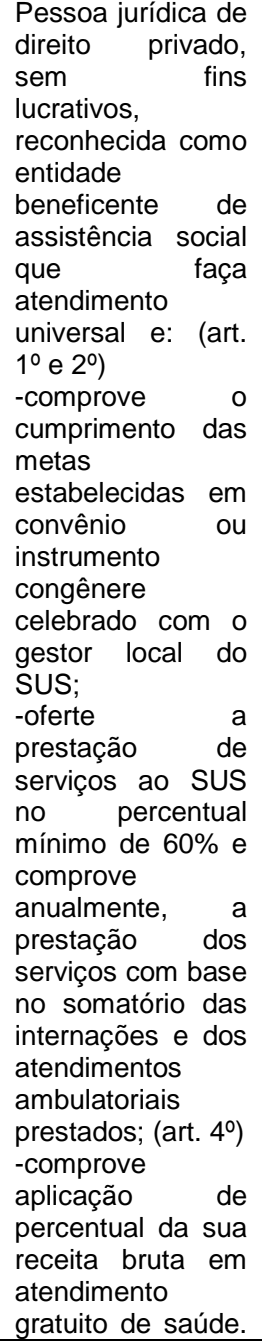 & 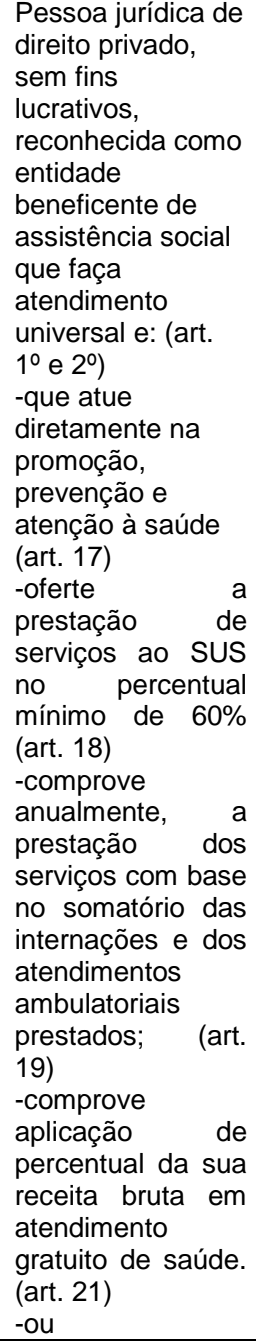 & 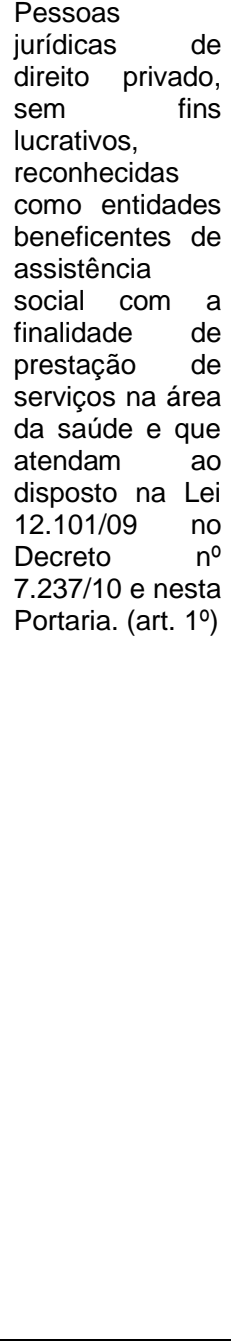 & 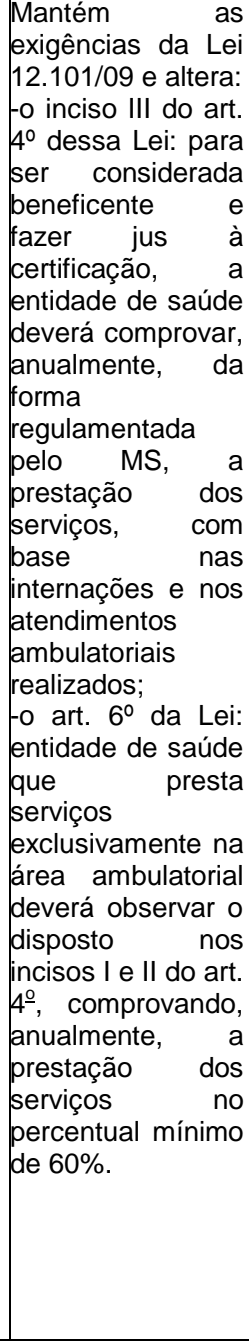 & $\begin{array}{l}\text { Pessoas } \\
\text { jurídicas de } \\
\text { direito privado, } \\
\text { sem fins } \\
\text { lucrativos, } \\
\text { reconhecidas } \\
\text { como entidades } \\
\text { beneficentes de } \\
\text { assistência } \\
\text { social com a } \\
\text { finalidade de } \\
\text { prestação de } \\
\text { serviços na área } \\
\text { da saúde e que } \\
\text { atendam ao } \\
\text { disposto na Lei } \\
12.101 / 09 \text { seu } \\
\text { Decreto } \\
\text { regulamentador } \\
\text { e nesta Portaria. } \\
\text { (art. 10) }\end{array}$ & 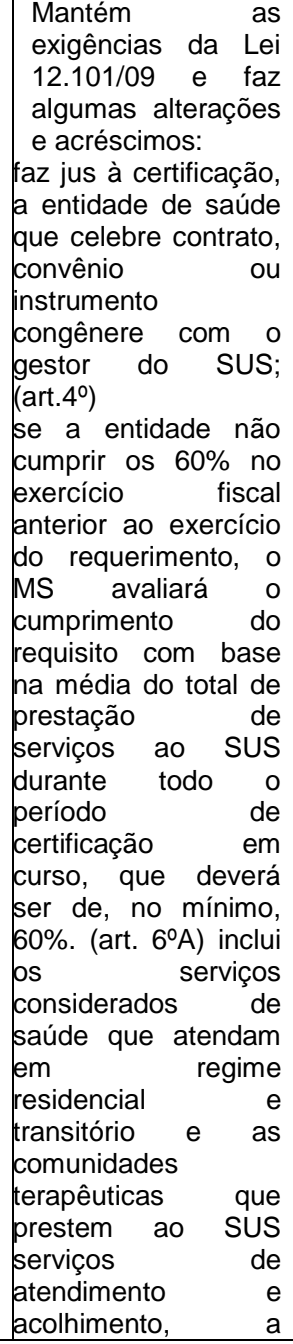 & $\begin{array}{l}\text { Pessoas } \\
\text { jurídicas de } \\
\text { direito privado, } \\
\text { sem fins } \\
\text { lucrativos, } \\
\text { reconhecidas } \\
\text { como entidades } \\
\text { beneficentes de } \\
\text { assistência } \\
\text { social com a } \\
\text { finalidade de } \\
\text { prestação de } \\
\text { serviços na área } \\
\text { da saúde e que } \\
\text { atendam ao } \\
\text { disposto na Lei } \\
\text { 12.101/09 (art. } \\
\text { 1) }\end{array}$ & 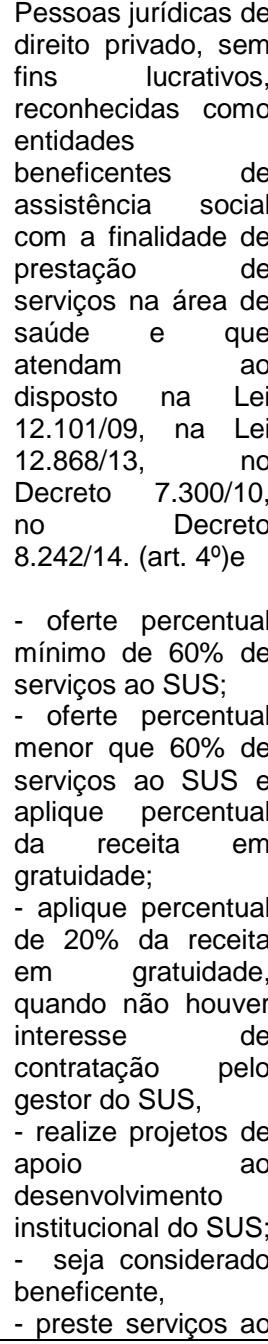 \\
\hline
\end{tabular}




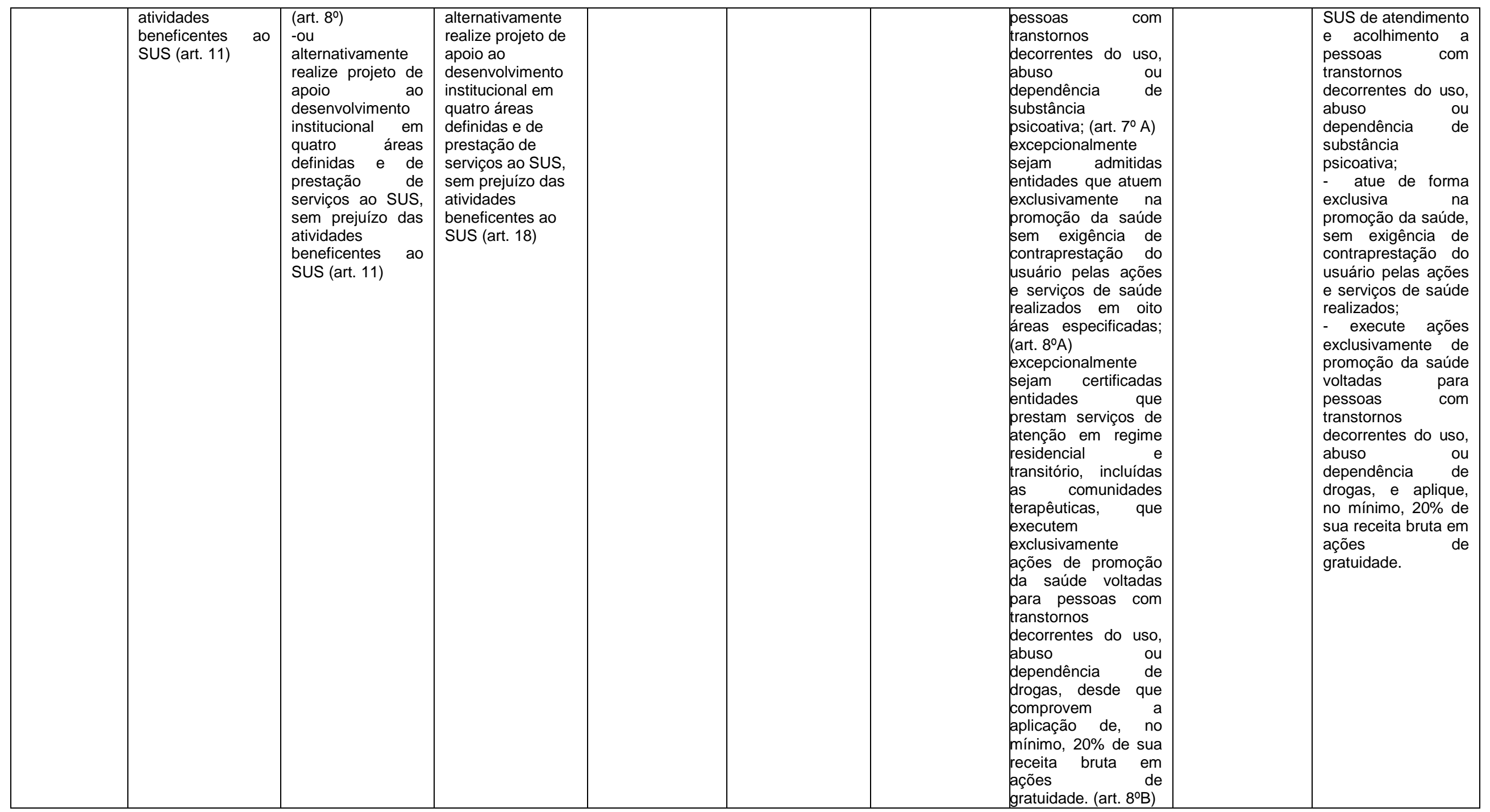




\begin{tabular}{|c|c|c|c|c|c|c|c|c|c|}
\hline & $M P$ no 446/08 & Lei no 12.101/09 & $\begin{array}{l}\text { Decreto } \\
7.237 / 10\end{array}$ & $\begin{array}{l}\text { Portaria } \\
3.355 / 10\end{array}$ & $\begin{array}{c}\text { Lei } \mathrm{n}^{\circ} \\
12.453 / 11\end{array}$ & $\begin{array}{l}\text { Portaria } \\
1.970 / 11\end{array}$ & Lei $n=12.868 / 13$ & $\begin{array}{l}\text { Decreto } \\
8.242 / 14\end{array}$ & $\begin{array}{c}\text { Portaria } \\
834 / 16\end{array}$ \\
\hline $\begin{array}{l}\text { Órgão } \\
\text { Julgador } \\
\text { para o } \\
\text { CEBAS- } \\
\text { SAÚDE }\end{array}$ & $\begin{array}{l}\text { Ministério da } \\
\text { Saúde (art. 22) }\end{array}$ & $\begin{array}{l}\text { Ministério } \quad \mathrm{da} \\
\text { Saúde }\end{array}$ & $\begin{array}{l}\text { Ministério da } \\
\text { Saúde }\end{array}$ & $\begin{array}{lr}\text { Secretaria } & \text { de } \\
\text { Atenção } & \text { à } \\
\text { Saúde } & \text { do } \\
\text { Ministério } & \text { da } \\
\text { Saúde } & \end{array}$ & & $\begin{array}{lr}\text { Secretaria } & \text { de } \\
\text { Atenção } & \text { à } \\
\text { Saúde } & \text { do } \\
\text { Ministério } & \text { da } \\
\text { Saúde } & \end{array}$ & & $\begin{array}{l}\text { Ministério da } \\
\text { Saúde }\end{array}$ & $\begin{array}{l}\text { Secretaria de } \\
\text { Atenção à Saúde - } \\
\text { SAS/MS, } \\
\text { Departamento de } \\
\text { Certificação de } \\
\text { Entidades } \\
\text { Beneficentes de } \\
\text { Assistência Social } \\
\text { em Saúde DCEBAS }\end{array}$ \\
\hline $\begin{array}{l}\text { Prazo de } \\
\text { Validade do } \\
\text { CEBAS- } \\
\text { SAÚDE }\end{array}$ & $\begin{array}{l}\text { Será fixado em } \\
\text { regulamento, } \\
\text { observadas as } \\
\text { especificidades de } \\
\text { cada uma das } \\
\text { áreas e o prazo } \\
\text { mínimo de } 1 \text { ano e } \\
\text { máximo de } 3 \text { anos } \\
\text { (art. } 22\end{array}$ & $\begin{array}{l}\text { Será fixado em } \\
\text { regulamento, } \\
\text { observadas as } \\
\text { especificidades de } \\
\text { cada uma das } \\
\text { áreas e o prazo } \\
\text { mínimo de } 1 \text { ano e } \\
\text { máximo de } 5 \\
\text { anos. (art. 21) }\end{array}$ & 3 anos (art. $\left.5^{\circ}\right)$ & $\begin{array}{l}3 \text { anos permitida } \\
\text { sua renovação } \\
\text { por iguais } \\
\text { períodos. (art. } \\
1^{\circ} \text { ) }\end{array}$ & & 3 anos & $\begin{array}{l}1 \text { a } 5 \text { anos (art. 21) } \\
5 \text { anos para as } \\
\text { certificações } \\
\text { concedidas ou que } \\
\text { vierem a ser } \\
\text { concedidas com } \\
\text { base na Lei para } \\
\text { requerimentos de } \\
\text { renovação } \\
\text { protocolados entre } \\
30 / 11 / 09 \text { e } 31 / 12 / 11 \\
\text { (art. 38A) }\end{array}$ & $\begin{array}{l}3 \text { anos para } \\
\text { certificações } \\
\text { originárias a } \\
\text { partir da Lei } \\
12.868 / 13 \text { (art. } \\
5^{\circ} \text { ) } \\
5 \text { anos para } \\
\text { certificações } \\
\text { renovadas a } \\
\text { partir da Lei } \\
12.868 / 13 \text { para } \\
\text { entidades com } \\
\text { receita anual } \\
\text { igual ou inferior } \\
\text { a R } \$ 1 \text { milhão } \\
\text { (art. } 5^{\circ} \text { ) } \\
\\
5 \text { anos para } \\
\text { certificações } \\
\text { concedidas ou } \\
\text { que vierem a ser } \\
\text { concedidas com } \\
\text { base na Lei para } \\
\text { requerimentos } \\
\text { de renovação } \\
\text { protocolados } \\
\text { entre } 30 / 11 / 09 \text { e } \\
31 / 12 / 11 \text { (art. } 56 \text { ) }\end{array}$ & $\begin{array}{l}\text { O CEBAS } \\
\text { concedido } \\
\text { originalmente tem } \\
\text { validade de } 3 \text { anos. } \\
\\
\text { O CEBAS renovado } \\
\text { tem validade de } 3 \\
\text { anos para entidades } \\
\text { com renda bruta } \\
\text { anual maior de } R \$ \\
1.000 .000,00 \text { e de } 5 \\
\text { anos para entidades } \\
\text { com receita bruta } \\
\text { igual ou inferior a } R \$ \\
1.000 .000,00 \text {. }\end{array}$ \\
\hline
\end{tabular}




\begin{tabular}{|c|c|c|c|c|c|c|c|c|c|}
\hline & $M P ~ n=446 / 08$ & Lei no 12.101/09 & $\begin{array}{l}\text { Decreto } \\
7.237 / 10\end{array}$ & $\begin{array}{l}\text { Portaria } \\
3.355 / 10\end{array}$ & $\begin{array}{c}\text { Lei } \mathrm{n}^{\circ} \\
12.453 / 11\end{array}$ & $\begin{array}{l}\text { Portaria } \\
1.970 / 11\end{array}$ & Lei no 12.868/13 & $\begin{array}{l}\text { Decreto } \\
8.242 / 14\end{array}$ & $\begin{array}{c}\text { Portaria } \\
834 / 16\end{array}$ \\
\hline \multirow[t]{2}{*}{$\begin{array}{l}\text { Pedido para } \\
\text { renovação } \\
\text { do CEBAS- } \\
\text { SAÚDE }\end{array}$} & $\begin{array}{l}\text { Renovação } \\
\text { automática }\end{array}$ & $\begin{array}{ll}6 \text { meses antes } & \text { do } \\
\text { vencimento } & \text { do } \\
\text { prazo } & \text { da } \\
\text { concessão } & \text { do } \\
\text { CEBAS-SAÚDE }\end{array}$ & $\begin{array}{l}6 \text { meses antes do } \\
\text { vencimento do } \\
\text { prazo da } \\
\text { concessão do } \\
\text { CEBAS-SAÚDE }\end{array}$ & $\begin{array}{l}\text { a) antecedência } \\
\text { mínima de } 6 \\
\text { meses do termo } \\
\text { final de sua } \\
\text { validade } \\
\text { b) entidade } \\
\text { certificada até o } \\
\text { dia } \\
\text { imediatamente } \\
\text { anterior ao da } \\
\text { publicação da } \\
\text { Lei no } 12.101 / \\
2009 \text {, poderá } \\
\text { requerer a } \\
\text { renovação do } \\
\text { Certificado até a } \\
\text { data de sua } \\
\text { validade. }\end{array}$ & & $\begin{array}{l}6 \text { meses antes } \\
\text { do vencimento } \\
\text { do prazo da } \\
\text { concessão em } \\
\text { vigor (art. 41) }\end{array}$ & $\begin{array}{l}360 \text { dias antes do } \\
\text { vencimento do } \\
\text { prazo da concessão } \\
\text { em vigor. } \\
\text { Considerados } \\
\text { tempestivos os } \\
\text { requerimentos } \\
\text { apresentados antes } \\
\text { do termo final de } \\
\text { validade da } \\
\text { certificação e } \\
\text { protocolados entre } \\
30 / 11 / 09 \text { e a } \\
\text { publicação da Lei no } \\
12.868 / 13 ; \\
\text { Excepcionalmente } \\
\text { tempestivos os } \\
\text { pedidos } \\
\text { protocolados entre } \\
30 / 11 / 09 \text { e } 31 / 12 / 10 \\
\text { no período de até } \\
360 \text { dias após o } \\
\text { termo final de } \\
\text { validade da } \\
\text { certificação }\end{array}$ & $\begin{array}{l}360 \text { dias antes } \\
\text { do vencimento } \\
\text { do prazo da } \\
\text { concessão para } \\
\text { as entidades } \\
\text { que tiveram seu } \\
\text { prazo de } \\
\text { validade } \\
\text { estendido, na } \\
\text { forma do art. 38- } \\
\text { A da Lei no } \\
12.101 / 09 \text {. (art. } \\
\text { 59) } \\
\text { Considerados } \\
\text { tempestivos os } \\
\text { requerimentos } \\
\text { apresentados } \\
\text { antes do termo } \\
\text { final de validade } \\
\text { da certificação e } \\
\text { protocolados } \\
\text { entre } 30 / 11 / 09 \text { e } \\
\text { a publicação } \\
\text { da Lei }{ }^{\circ} \\
12.868 / 13 \text { (art. } \\
60 \text { ) } \\
\text { Excepcionalmen } \\
\text { te tempestivos } \\
\text { os pedidos } \\
\text { protocolados } \\
\text { entre } 30 / 11 / 09 \text { e } \\
31 / 12 / 10 \text { no } \\
\text { período de até } \\
360 \text { dias após o } \\
\text { termo final de } \\
\text { validade da } \\
\text { certificação (art. } \\
60 \text { ) }\end{array}$ & $\begin{array}{l}\text { protocolado no } \\
\text { decorrer dos } 360 \\
\text { dias que antecedem } \\
\text { o termo final de } \\
\text { validade do } \\
\text { certificado; antes de } \\
360 \text { dias não serão } \\
\text { conhecidos. }\end{array}$ \\
\hline & $\mathrm{MP} \mathrm{n}^{\circ} 446 / 08$ & Lei $n^{0} 12.101 / 09$ & Decreto & Portaria & Lei $n^{\circ}$ & Portaria & Lei $n^{0} 12.868 / 13$ & Decreto & Portaria 834/16 \\
\hline
\end{tabular}




\begin{tabular}{|c|c|c|c|c|c|c|c|c|c|}
\hline & & & $7.237 / 10$ & $3.355 / 10$ & $12.453 / 11$ & $1.970 / 11$ & & $8.242 / 14$ & \\
\hline $\begin{array}{l}\text { Opções } \\
\text { para a não } \\
\text { oferta de } \\
60 \% \\
\text { serviços ao } \\
\text { SUS }\end{array}$ & $\begin{array}{l}\text { aplique percentual } \\
\text { de sua receita } \\
\text { bruta em } \\
\text { atendimento } \\
\text { gratuito, na falta } \\
\text { de demanda } \\
\text { declarada pelo } \\
\text { gestor do SUS, da } \\
\text { seguinte forma: } \\
\text { I-20\%, se o } \\
\text { percentual de } \\
\text { atendimento ao } \\
\text { SUS for inferior a } \\
\text { 30\%;; II - 10\%, se } \\
\text { o percentual de } \\
\text { atendimento ao } \\
\text { SUS for igual ou } \\
\text { superior a } 30 \text { e } \\
\text { inferior a } 50 \% ; \text { ou } \\
\text { III - 5\%, se o } \\
\text { percentual de } \\
\text { atendimento ao } \\
\text { SUS for igual ou } \\
\text { superior a } 50 \% \text { ou } \\
\text { se completar o } \\
\text { quantitativo das } \\
\text { internações } \\
\text { hospitalares } \\
\text { (art.8\%) ou } \\
\text { alternativamente } \\
\text { realize projeto de } \\
\text { apoio ao } \\
\text { desenvolvimento } \\
\text { institucional em } \\
\text { quatro áreas } \\
\text { definidas e de } \\
\text { prestação de } \\
\text { serviços ao SUS, } \\
\text { sem prejuízo das } \\
\text { atividades } \\
\text { beneficentes ao } \\
\text { SUS (art. } 11 \text { ) }\end{array}$ & $\begin{array}{l}\text { aplique percentual } \\
\text { de sua receita bruta } \\
\text { em atendimento } \\
\text { gratuito, na falta de } \\
\text { demanda declarada } \\
\text { pelo gestor do SUS, } \\
\text { da seguinte forma: } \\
\text { I - } 20 \% \text {, se o } \\
\text { percentual de } \\
\text { atendimento ao SUS } \\
\text { for inferior a } 30 \% ; ; \\
\text { II - } 10 \% \text {, se o } \\
\text { percentual de } \\
\text { atendimento ao SUS } \\
\text { for igual ou superior } \\
\text { a } 30 \text { e inferior a } \\
50 \% \text {; ou } \\
\text { III-5\%, se o } \\
\text { percentual de } \\
\text { atendimento ao SUS } \\
\text { for igual ou superior } \\
\text { a } 50 \% \text { ou se } \\
\text { completar o } \\
\text { quantitativo das } \\
\text { internações } \\
\text { hospitalares ou } \\
\text { atendimento } \\
\text { ambulatorial (art. } 8 \text { o) } \\
\text { ou alternativamente } \\
\text { realize projeto de } \\
\text { apoio ao } \\
\text { desenvolvimento } \\
\text { institucional em } \\
\text { quatro áreas } \\
\text { definidas e de } \\
\text { prestação de } \\
\text { serviços ao SUS, } \\
\text { sem prejuízo das } \\
\text { atividades } \\
\text { beneficentes ao } \\
\text { SUS (art. } 11 \text { ) }\end{array}$ & $\begin{array}{l}\text { aplique percentual } \\
\text { de sua receita } \\
\text { bruta em } \\
\text { atendimento } \\
\text { gratuito, na falta } \\
\text { de demanda } \\
\text { declarada pelo } \\
\text { gestor do SUS, da } \\
\text { seguinte forma: } \\
\text { I- } 20 \% \text {, se o } \\
\text { atendimento ao } \\
\text { SUS for inferior a } \\
30 \% ; ; \\
\text { II } 10 \% \text {, se o } \\
\text { atendimento ao } \\
\text { SUS for igual ou } \\
\text { superior a } 30 \text { e } \\
\text { inferior a } 50 \% ; \text { ou } \\
\text { III - 5\%, se o } \\
\text { atendimento ao } \\
\text { SUS for igual ou } \\
\text { superior a } 50 \% \text { ou } \\
\text { se completar o } \\
\text { quantitativo das } \\
\text { internações } \\
\text { hospitalares ou } \\
\text { atendimento } \\
\text { ambulatorial (art. } \\
21 \text { ) } \\
\text { alternativamente } \\
\text { realize projeto de } \\
\text { apoio ao } \\
\text { desenvolvimento } \\
\text { institucional em } \\
\text { quatro áreas } \\
\text { definidas e de } \\
\text { prestação de } \\
\text { serviços ao SUS, } \\
\text { sem prejuízo das } \\
\text { atividades } \\
\text { beneficentes ao } \\
\text { SUS (art. 18) }\end{array}$ & $\begin{array}{l}\text { aplique percentual } \\
\text { de sua receita } \\
\text { bruta em } \\
\text { atendimento } \\
\text { gratuito, na falta } \\
\text { de demanda } \\
\text { declarada pelo } \\
\text { gestor do SUS, da } \\
\text { seguinte forma: } \\
\text { I- } 20 \% \text {, se o } \\
\text { atendimento ao } \\
\text { SUS for inferior a } \\
30 \% ; ; \\
\text { II } 10 \% \text {, se o } \\
\text { atendimento ao } \\
\text { SUS for igual ou } \\
\text { superior a } 30 \text { e } \\
\text { inferior a } 50 \% ; \text { ou } \\
\text { III-5\%, se o } \\
\text { atendimento ao } \\
\text { SUS for igual ou } \\
\text { superior a } 50 \% \text { ou } \\
\text { se completar o } \\
\text { quantitativo das } \\
\text { internações } \\
\text { hospitalares ou } \\
\text { atendimento } \\
\text { ambulatorial (art. } \\
21 \text { ) } \\
\text { alternativamente } \\
\text { realize projeto de } \\
\text { apoio ao } \\
\text { desenvolvimento } \\
\text { institucional em } \\
\text { quatro áreas } \\
\text { definidas e de } \\
\text { prestação de } \\
\text { serviços ao SUS, } \\
\text { sem prejuízo das } \\
\text { atividades } \\
\text { eneficentes ao } \\
\text { SUS (art. 18) }\end{array}$ & & $\begin{array}{l}\text { Explicita os } \\
\text { documentos } \\
\text { necessários } \\
\text { para } \\
\text { comprovação da } \\
\text { gratuidade } \\
\text { conforme a Lei } \\
12.101 / 09\end{array}$ & $\begin{array}{lrr}\text { será admitida a } \\
\text { avaliação } & \text { pelo } \\
\text { Ministério } & \text { da } \\
\text { Saúde } & \text { caso a } \\
\text { entidade r } & \text { tenha } \\
\text { cumprido, } & \text { no } \\
\text { mínimo, } & 50 \% \\
\text { (cinquenta } & \text { por } \\
\text { cento) } & \text { da } \\
\text { prestação de seus } \\
\text { serviços ao SUS }\end{array}$ & $\begin{array}{l}\text { Entidade não } \\
\text { contratada pelo } \\
\text { gestor } \\
\text { Programas e } \\
\text { estratégicas } \\
\text { prioritárias } \\
\text { definidas pelo } \\
\text { Ministério da } \\
\text { Saúde }\end{array}$ & \\
\hline
\end{tabular}




\section{Discussão}

Primeiramente, destacam-se as pessoas jurídicas legitimadas para obtenção do CEBAS que são de direito privado, sem fins lucrativos, reconhecidas como entidades beneficentes de assistência social com a finalidade de prestação de serviços nas áreas de assistência social, saúde ou educação, que realizem atendimento universal.

Quanto aos legitimados para obtenção do CEBAS-SAÚDE, inicialmente a certificação era destinada às entidades de direito privado, sem fins lucrativos, que ofertassem diretamente seus serviços ao SUS, no percentual mínimo de $60 \%$ ou no caso de entidades de saúde de reconhecida excelência, que apresentassem projetos de apoio ao desenvolvimento institucional do SUS em algumas áreas de atuação definidas, conforme preconizado tanto na MP o 446 de 2008, como na Lei № 12.101, de 2009.

Com a edição do Decreto № 7.237 de 2010, (12) observa-se uma especificação das entidades beneficentes de assistência social na área de saúde, definindo que são aquelas que atuem diretamente na promoção, prevenção e atenção à saúde, utilizando terminologia semelhante àquela do $\S^{1^{\circ}}$ do art. $2^{\circ}$ da Lei 8.080 de 1990 , (13) que refere como direito do cidadão o acesso a ações e serviços de saúde para a sua promoção, proteção e recuperação, quando os art. $1^{\circ}$ e $2^{\circ}$ da Lei 12.101 de 2009 estabelecem genericamente que essas entidades são pessoas jurídicas de direito privado, sem fins lucrativos, que prestam serviço na área de saúde e que obedecem ao princípio da universalidade do atendimento.

Ocorre, todavia que no sistema jurídico brasileiro, um decreto não tem o condão de inovar no ordenamento legal, mas tão somente de regulamentar ou propiciar a execução correta de uma lei, não podendo ir contra ou além da lei. Assim, o Decreto no 7.237, de 2010, ao especificar esses legitimados ampliou e incluiu entidades que precisavam de normas específicas para sua admissão.

Tal situação só foi sanada com a edição da Lei oㅜ 12.868, de 2013, (14) que deu nova redação a alguns artigos e incluiu outros na Lei 12.101 de 2009, ao introduzir a possibilidade de certificação de entidades que atuassem exclusivamente na promoção da saúde e definindo que seriam consideradas como ações e serviços de promoção da saúde as atividades voltadas para redução de risco à saúde, desenvolvidas em oito áreas especificadas no seu art. 6ㅇ. A mencionada lei passou a permitir que comunidades 
terapêuticas, em regime residencial e transitório, que prestassem ao SUS serviços de atendimento e acolhimento a pessoas com transtornos decorrentes do uso, abuso ou dependência de substância psicoativa, pudessem solicitar o CEBAS-SAÚDE.

O Decreto o 8.242 de 2014, (15) que regulamenta a Lei 12.101 de 2009 e revoga o Decreto 7.237 de 2010, repete o texto da Lei 12.868 de 2013, adicionando as entidades que atuassem exclusivamente na promoção da saúde, no rol daquelas que poderiam solicitar a certificação, o que o Decreto 7.237 de 2010 não previa.

Note-se o inciso V do artigo 5ำ da Portaria/GM/MS 131 de 26 de janeiro de 2012 (16) que traz como requisito para concessão de incentivo financeiro às comunidades terapêuticas a necessidade do CEBAS-SAÚDE, ou seja, antes mesmo da instituição da Lei № 12.868, de 2013, para receber recursos financeiros do Ministério da Saúde essas entidades deveriam ser detentoras do certificado, mesmo que a lei não previsse esta obrigação.

No decorrer do processo de implantação da Lei 12.101 de 2009 surgiram alguns questionamentos sobre quais entidades poderiam requerer certificação como entidade beneficente de assistência social, em especial o caso de entidades estatais, constituídas sob regime de direito privado, serem certificadas com base na legislação vigente.

Tal questionamento foi suscitado no Grupo de Trabalho do CEBAS da AdvocaciaGeral da União e não houve consenso. Entretanto, no entendimento da Advocacia Geral da União - Consultoria Jurídica junto ao Ministério da Saúde, por meio do Parecer 008/2012/GBA/CGU/AGU, há possibilidade de entidades públicas constituídas sob regime jurídico de direito privado, como por exemplo, empresas públicas, sociedades de economia mista, consórcios públicos de direito privado, dentre outras, desde que prestadoras de serviços públicos de saúde, serem certificadas desde que atendam aos requisitos da lei (17). Dessa forma, a Procuradoria Geral da Fazenda Nacional passou a adotar essa posição, apesar das controvérsias sobre o assunto. (18)

Ainda em relação à MP no 446, de 2008, uma das inovações é a retirada das atribuições do Conselho Nacional de Assistência Social - CNAS para certificar as entidades beneficentes de assistência social e a sua transferência para os Ministérios do Desenvolvimento Social e Combate à Fome, da Saúde e da Educação, de acordo com a respectiva área de atuação da entidade, conforme seu artigo 22. 
Como se percebe, houve uma desconcentração de atividades da certificação das entidades beneficentes de assistência social, que no Poder Executivo se justifica pelo fato de cada órgão setorial da União dispor de conhecimento técnico diretamente voltado para a sua área de atuação, o que facilita o estudo das atividades desempenhadas pelas respectivas entidades e o julgamento do pedido de concessão de certificação (19).

Entretanto, com a rejeição da Medida Provisória ํㅡ 446, de 2008, pelo Congresso Nacional, em 10 de fevereiro de 2009, foi restabelecida a vigência da Lei oㅡ 8.742, de 1993, com o retorno da competência para a emissão de CEBAS ao CNAS, onde permaneceu por pouco mais de nove meses até a publicação da Lei ㄲo 12.101, de 2009. Desde então e conforme estabelecido, nas portarias que definem os procedimentos relativos à certificação das entidades beneficentes de assistência social na área de saúde, editadas pelo MS, Portaria GM/MS № 1.970, de 2011 e Portaria/GM/MS 834, de 2016, compete à Secretaria de Atenção à Saúde, por meio do Departamento de Certificação de Entidades Beneficentes de Assistência Social em Saúde-DCEBAS, deliberar sobre a certificação. (20) (21)

Em relação ao prazo de validade do certificado também se verificam modificações relevantes. No início do período analisado e de vigência da Medida Provisória era de três anos, mas a Lei 12.101 de 2009 estabeleceu a possibilidade do certificado ter o prazo de um a cinco anos. Ao regulamentar a lei o Decreto no 7.237 de 2010 estabeleceu em três anos a certificação, pois havia a interpretação de que a Fazenda Pública poderia ter seu crédito prescrito se prazo estabelecido fosse de cinco anos e houvesse um cancelamento a posteriori, em virtude de alguma irregularidade por parte da entidade legitimada.

Contudo, tal precaução não ocorreu com a edição da Lei no 12.868 , de 2013, que prevê o prazo de cinco anos do certificado para os pedidos de renovação protocolados entre 30 de novembro de 2009 e 31 de dezembro de 2011.

Na evolução legislativa do CEBAS a renovação automática foi tratada no artigo 37 da MP ํㅜ 446, de 2008, ao estabelecer que os processos de renovação do certificado que não tivessem sido julgados, julgados e pendentes de recursos, seriam automaticamente deferidos e as representações em curso propostas em face da renovação ficariam prejudicadas. Como resultado, pelo menos 7.400 entidades beneficentes tiveram seus certificados renovados automaticamente (22) (23) (24). E ainda o legislador previu que as entidades certificadas cujas titulações fossem expirar no prazo de doze meses a contar da 
publicação do ato (10 de novembro de 2008), não precisariam pleitear a renovação do CEBAS, já que conforme seu artigo 41 , os certificados seriam automaticamente renovados pelo prazo de doze meses.

Para tentar reverter a renovação automática, o Ministério Público Federal propôs Arguição de Descumprimento de Preceito Fundamental, № 265, de 2012 perante o Supremo Tribunal Federal com o propósito de que fosse declarada a inconstitucionalidade dos artigos 37, 38 e 39 da MP № 446, de 2008, já que sem lei que estabelecesse os requisitos para imunidade seriam violados, em tese, os princípios da solidariedade, da universalidade do custeio da seguridade social, da legalidade, da moralidade e da impessoalidade. A Advocacia-Geral da União sustentou que são válidos os certificados de isenção de impostos concedidos enquanto a MP esteve em vigor. Atualmente, os autos estão conclusos ao relator (25).

Como dito anteriormente, o Congresso Nacional rejeitou a MP oㅡ 446, de 2008, em 10 de fevereiro de 2009. Entretanto, não editou Decreto Legislativo, previsto no art. 62, § 11, da Constituição Federal, que é o instrumento apto para reger as relações jurídicas decorrentes da rejeição da MP.

Dessa forma, as relações jurídicas constituídas e os atos praticados durante a vigência da MP seriam por ela conservados, em decorrência da segurança jurídica e respeito do direito adquirido à renovação do CEBAS. Nesse sentido, a Nota DECOR/CGU/AGU № 180/2009-JGAS da Consultoria Jurídica junto ao Ministério da Previdência Social (26), afirma que as relações jurídicas que se formaram sob a égide das regras previstas nos artigos 37; 38; 39; 40 e 41 da Medida Provisória oㅡ 446, de 2008, bem como aquelas decorrentes de atos praticados pela Administração Pública Federal durante o seu período de vigência, continuarão sendo regidas pela citada Medida Provisória.

Com a edição da Lei 12.101, de 2009, o pedido de renovação passou a ser novamente submetido a análise do Ministério competente, sendo que seu requerimento passou de seis meses para trezentos e sessenta dias, como se observa no $\S 1^{\circ}$ do artigo 24, posteriormente alterado pela Lei 12.868, de 2013 permitindo que os requerimentos de renovação intempestivos fossem convertidos em tempestivos, caso fossem protocolados até a data final do certificado ou até trezentos e sessenta dias após a validade do certificado no período entre 30 de novembro de 2009 e 31 de dezembro de 2010. 
A Portaria 834, de 2016, abre a possibilidade de protocolar o requerimento de concessão ou renovação do CEBAS por meio de sistema eletrônico disponível no endereço www.saude.gov.br/cebas-saude e que está em processo de implantação.

Outro ponto de investigação foi a variação de alternativas pela não prestação de serviços no mínimo de $60 \%$ ao SUS, já que este é um dos requisitos principais para o CEBAS-SAÚDE. A Lei ํㅜ 12.868 , de 2013 , incluiu o $\S 3^{\circ}$ no art. $4^{\circ}$ possibilitando que entidades que aderirem a programas e estratégias prioritárias definidas pelo Ministério da Saúde recebam um adicional de até $10 \%$ em seus serviços prestados ao SUS e ainda incluiu o art. 6--A que prevê, nos casos de renovação, a possibilidade do cumprimento do requisito de $60 \%$ de serviços prestados, com base na média durante todo o período de certificação em curso desde que a entidade cumpra, no mínimo, $50 \%$ da prestação de seus serviços em cada um dos anos do período de certificação.

Desde a edição da MP 446, de 2008 foi definida a opção da entidade de saúde de reconhecida excelência realizar, alternativamente, projetos de apoio ao desenvolvimento institucional do SUS, celebrando ajuste com a União, por intermédio do Ministério da Saúde, nas seguintes áreas de atuação: estudos de avaliação e incorporação de tecnologias; capacitação de recursos humanos; pesquisas de interesse público em saúde; ou desenvolvimento de técnicas e operação de gestão em serviços de saúde; essa proposta foi incluída na Lei 12.101, de 2009.

A Lei 12.453, de 2011 mantém as exigências da Lei 12.101/09 e altera dois itens dessa Lei: o inciso III do art. 4 estabelecendo que para ser considerada beneficente e fazer jus à certificação, a entidade de saúde deverá comprovar, anualmente, da forma regulamentada pelo MS, a prestação dos serviços, com base nas internações e nos atendimentos ambulatoriais realizados; e 0 art. 6o definindo que a entidade de saúde que presta serviços exclusivamente na área ambulatorial deverá observar o disposto nos incisos I e II do art. $4^{\circ}$, comprovando, anualmente, a prestação dos serviços no percentual mínimo de 60\%. (27)

Quanto à aplicação da receita em gratuidade, verifica-se também a variação da aplicação de porcentagem de $5 \%$ a $20 \%$ de sua receita na área de saúde, de maneira inversamente proporcional à porcentagem de serviços prestados ao SUS, ou seja, quanto maior a prestação de serviços ao SUS menor a necessidade de aplicação em gratuidade, conforme o artigo $8^{\circ}$ da Lei ํㅜ 12.101, de 2009. Esta variação é uma inovação e não está 
prevista no Decreto no 2.536, de 1998, que estabelecia a aplicação de pelo menos vinte por cento da receita bruta anualmente, em gratuidade, pela entidade caso não prestasse seus serviços ao SUS no percentual mínimo de 60\%.

E por fim, não havendo interesse do gestor local do SUS na contratação dos serviços ou se o percentual de prestação de serviços ao SUS for inferior a 30\%, a entidade deverá aplicar $20 \%$ da sua receita em gratuidade na área da saúde conforme 0 art. 6ํำ da Lei no 12.868, de 2013 e do inciso I do art. 8o da Lei ํo 12.101, de 2009.

As ações de gratuidade devem ser pactuadas com o gestor do SUS e formalizadas no instrumento contratual. Pode-se citar como ações de gratuidade, conforme o anexo II da Portaria/GM/MS 1.970, de 2011, a) casas de apoio, que visem a manutenção de instalações físicas para o apoio e suporte a pacientes em trânsito para tratamento, b) apoio na formação de profissionais da saúde, c) promoção as ações de educação junto à população local, dentre outras pactuadas com o gestor do SUS, confirmadas na Portaria/GM/MS 834, de 2016.

\section{Considerações Finais}

Como se observou no presente estudo, a contratualização de entidades privadas corresponde a uma realidade na prestação de serviços de saúde para o SUS, e o CEBASSAÚDE é uma qualificação importante para as entidades beneficentes da área de saúde, já que é requisito para a isenção da cota patronal da contribuição previdenciária junto à Receita Federal, além de permitir a entidade que obtenha recursos federais.

No decorrer do trabalho, verificou-se que foram editados nove atos normativos referentes às disposições de concessão e de renovação da certificação de entidades beneficentes de assistência social em saúde, no período de 2008 a 2016, inclusive a recente Portaria/GM/MS 834, de 2016, que revisa e atualiza o processo de certificação a partir das constatações decorrentes da aplicação e das alterações da Lei 12.101, de 2009 pela Lei 12.868 , de 2013.

De um modo geral, conclui-se que o alargamento dos legitimados, a expertise do órgão julgador na área de atuação da entidade, o aumento de prazo de validade do certificado nos casos de renovação em alguns casos, e da extensão do prazo para o pedido para renovação e a crescente alternativas para não prestação de $60 \%$ de seus serviços ao SUS, sem dúvida, são benéficos às entidades de assistência social em saúde. 
Entretanto, é necessário ponderar se tais contribuições estão de acordo e fortalecem a prestação de serviços de saúde no SUS, tendo em vista o cenário atual de agravamento do financiamento direto ao SUS. Pode haver uma tendência do sistema público de saúde ficar dependente das instituições privadas e ainda ficar sem a prestação de serviços de assistência à saúde por essas instituições, caso elas optem pelas alternativas definidas na lei, de aplicação de percentual em gratuidade, como por exemplo, a manutenção de casas de apoio, a formação de recursos humanos, gerenciamento de programas, dentre outras pactuadas com o gestor do SUS, como vimos no decorrer do trabalho.

A possibilidade de aplicação de $20 \%$ da receita da entidade em gratuidade sem a necessidade de oferta de serviços de assistência ao SUS e a extensão do prazo de validade para cinco anos para os pedidos de renovação protocolados entre 30 de novembro de 2009 e 31 de dezembro de 2011 para entidades com receita bruta anual igual ou inferior a um milhão de reais são situações que toda sociedade civil e órgãos de fiscalização devem atentar.

Cabe ao Estado promover e incentivar o surgimento de novas entidades que prestem auxílio na área da educação, saúde e assistência social por meio de subsídios e incentivos fiscais, como exposto no $\S^{\circ}$ do art. 195 da Constituição Federal e de acordo com suas leis reguladoras. Entretanto, tais promoções e incentivos não devem estar vinculados aos interesses privados das entidades em detrimento do interesse público.

Por fim, há de existir uma estabilidade jurídica para que as pessoas envolvidas naquela normatização conheçam a regra do jogo e saibam seus direitos e obrigações previamente, e não uma modificação quase anual dessas regras, sob pena de trazer insegurança jurídica neste processo, prejudicando aquelas entidades que realmente cumprem a lei e seu papel estatutário beneficente.

\section{Referências}

1 Brasil. Ministério da Saúde. Manual de orientações de serviços no Sistema Único de Saúde [Internet]. Brasília: 2007. [Acesso em 1 nov 2015]. Disponível em: http://bvsms.saude.gov.br/bvs/publicacoes/manual_orientacoes_contratacao_servicos_sus. pdf

2 Brasil. Secretaria da Receita Federal. Receita Federal Demonstrativos de Gastos Tributários PLOA 2015 (DGT 2015). Brasília, 2015. [Acesso em 9 nov 2015]. Disponível em 
http://idg.receita.fazenda.gov.br/dados/receitadata/gastos-tributarios/previsoesploa/arquivos-e-imagens/dgt-2015

3 Brasil. Instituto Brasileiro de Geografia e Estatística. As Fundações Privadas e Associações sem Fins Lucrativos no Brasil 2010. Rio de Janeiro, [Acesso em 1 nov 2015]. Disponível em: http://biblioteca.ibge.gov.br/visualizacao/livros/liv62841.pdf

4 Mendes, A. Tempos turbulentos da saúde pública brasileira: os impasses do financiamento no capitalismo financeirizado. São Paulo: Hucitec, 2012.

5 Ocké-Reis, CO. Mensuração dos gastos tributários: o caso dos planos de saúde - 20032011. Brasília, DF: Ipea, 2013.

6 Brasil. Poder Executivo. Medida Provisória no 446, de 7 de novembro de 2009. Dispõe sobre a certificação das entidades beneficentes de assistência social, regula os procedimentos de isenção de contribuições para a seguridade social, e dá outras providências. Diário Oficial da União, Brasília, 10 nov.2008. [Acesso em 18 set 2015]. Disponível em: http://www2.camara.leg.br/legin/fed/medpro/2008/medidaprovisoria-446-7novembro -2008-583387-publicacaooriginal-106225-pe.html.

7 Brasil. Poder Legislativo. Lei no 12.101, de 27 de novembro de 2009. Dispõe sobre a certificação das entidades beneficentes de assistência social; regula os procedimentos de isenção de contribuições para a seguridade social; altera a Lei no 8.742, de 7 de dezembro de 1993; revoga dispositivos das Leis nos 8.212, de 24 de julho de 1991, 9.429, de 26 de dezembro de 1996, 9.732, de 11 de dezembro de 1998, 10.684, de 30 de maio de 2003, e da Medida Provisória no 2.187-13, de 24 de agosto de 2001; e dá outras providências. Diário Oficial da União, Brasília, 30 nov.2009, [Acesso em 18 set 2015]. Disponível em: http://www.planalto.gov.br/ccivil_03/_ato2007-2010/2009/lei/112101.html

8 Amaro, L. Direito tributário brasileiro. 9ae ed. São Paulo: Saraiva, 2003.

9 Brasil. Lei 8.742 de 07 de dezembro de 1993. Dispõe sobre a organização da Assistência Social e dá outras providências. [Acesso em 15 nov 2016]. Disponível em: http://www.planalto.gov.br/ccivil_03/Leis/L8742.htm.

10 Brasil. Poder Executivo. Decreto 2.536 de 06 de abril de 1998. Dispõe sobre a concessão do Certificado de Entidade de Fins Filantrópicos a que se refere o inciso IV do art. 18 da Lei no 8.742, de 7 de dezembro de 1993, e dá outras providências. [Acesso em 5 nov 2016]. Disponível em:

https://www.planalto.gov.br/ccivil_03/decreto/D2536impressao.htm

11 Brasil. Poder Executivo. Decreto 3.504 de 13 de junho de 2000. Altera dispositivos do Decreto $\mathrm{n}^{\circ}$ 2.536, de 6 de abril de 1998, que dispõe sobre a concessão do Certificado de Entidade de Fins Filantrópicos a que se refere o inciso IV do art. 18 da Lei $n^{\circ} 8.742$, de 7 de dezembro de 1993. [Acesso em 5 nov 2016]. Disponível em: https://www.planalto.gov.br/ccivil_03/decreto/D3504impressao.htm 
12 Brasil. Poder Executivo. Decreto o 7.237, de 20 de julho de 2010. Regulamenta a Lei no 12.101, de 27 de novembro de 2009, para dispor sobre o processo de certificação das entidades beneficentes de assistência social e sobre procedimentos de isenção das contribuições para a seguridade social. Diário Oficial da União, Brasília, 21 jul.2010 [Acesso em 18 set 2015]. Disponível em: http://www.planalto.gov.br/ccivil_03/_ato20072010/2010/Decreto/D7237.html

13 Brasil. Poder Legislativo. Lei 8.080 de 19 de setembro de 1990. Dispõe sobre as condições para a promoção, proteção e recuperação da saúde, a organização e o funcionamento dos serviços correspondentes e dá outras providências. [Acesso em 18 set 2015]. Disponível em: http://www.planalto.gov.br/ccivil_03/leis/L8080.htm

14 Brasil. Poder Legislativo. Lei oㅜ 12.868 de 15 de outubro de 2013. Altera a Lei no 12.793, de 2 de abril de 2013, para dispor sobre o financiamento de bens de consumo duráveis a beneficiários do Programa Minha Casa, Minha Vida (PMCMV); constitui fonte adicional de recursos para a Caixa Econômica Federal; altera a Lei no 12.741, de 8 de dezembro de 2012, que dispõe sobre as medidas de esclarecimento ao consumidor, para prever prazo de aplicação das sanções previstas na Lei no 8.078, de 11 de setembro de 1990; altera as Leis no 12.761, de 27 de dezembro de 2012, no 12.101, de 27 de novembro de 2009, no 9.532, de 10 de dezembro de 1997, e no 9.615, de 24 de março de 1998; e dá outras providências. Diário Oficial da União, Brasília, 16 out.2013. [Acesso em 18 set 2015]. Disponível em: http://www.planalto.gov.br/ccivil_03/_Ato20112014/2013/Lei/L12868.htm\#art9

15 Brasil. Poder Executivo. Decreto o 8.242 de 23 de maio de 2014. Regulamenta a Lei no 12.101 , de 27 de novembro de 2009, para dispor sobre o processo de certificação das entidades beneficentes de assistência social e sobre procedimentos de isenção das contribuições para a seguridade social. Diário Oficial da União, Brasília, 26 mai.2014. [Acesso em 10 nov 2015]. Disponível em: http://www.planalto.gov.br/ccivil_03/_ato20072010/2010/Decreto/D7237.html

16 Brasil. Ministério da Saúde. Portaria/GM/MS 131 de 26 de janeiro de 2012. Institui incentivo financeiro de custeio destinado aos estados, municípios e ao D F para apoio ao custeio de Serviços de Atenção em Regime Residencial, incluídas as Comunidades Terapêuticas, voltados para pessoas com necessidades decorrentes do uso de álcool, crack e outras drogas, no âmbito da Rede de Atenção Psicossocial. [Acesso em 18 set 2015]. Disponível em: http://bvsms.saude.gov.br/bvs/saudelegis/gm/2012/prt0131_26_01_2012.html

17 Brasil. Ministério da Saúde. Consultoria Jurídica. Despacho no 2899/2013 FB/ COGEJUR/CONJUR-MS/CGU/AGU, Processo SIPAR no 25000.666489/2009-54. [Acesso em 22 nov 2015]. Disponível em: http://u.saude.gov.br/images/pdf/2014/novembro/10/22313.pdf

18 Brasil. Ministério da Fazenda. Parecer № 1344/2013. Isenção/Imunidade. Certificação de Entidades Beneficentes de Assistência Social. Relatório final do Grupo de Trabalho instituído pela Portaria AGU n 488/2011, com Despacho do Consultor-Geral da União e 
aprovação Ministerial. Desdobramento das discussões do GT. Parecer 008/2012/GBA/CGU/AGU. Despacho CGU 1700/2012. Aprovação Ministerial. [Acesso em 5 nov 2016]. Disponível em:

http://dados.pgfn.fazenda.gov.br/dataset/pareceres/resource/13442013

19 Brasil. Poder Executivo. Mensagem n 865, de 2009, Medida Provisória nำ446, de 2008. [Acesso em 30 out 2015]. Disponível em: http://www.camara.gov.br/sileg/integras/632451.pdf

20 Brasil. Ministério da Saúde. Portaria/GM/MS 1.970 de 16 de agosto de 2011. Dispõe sobre o processo de Certificação das Entidades Beneficentes de Assistência Social na área da Saúde (CEBAS-SAÚDE). Diário Oficial da União, Brasília, 17 ago.2011. [Acesso em 18 de setembro de 2015]. Disponível em:

http://bvsms.saude.gov.br/bvs/saudelegis/gm/2011/prt1970_16_08_2011.html

21 Brasil. Ministério da Saúde. Portaria/GM/MS 834 de 26 de abril de 2016. Redefine os procedimentos relativos à certificação das entidades beneficentes de assistência social na área de saúde. [Acesso em 8 nov 2016]. Disponível em:

bvsms.saude.gov.br/bvs/saudelegis/gm/2016/prt0834_26_04_2016.html

22 Brasil. Ministério do Desenvolvimento Social e Combate à Fome. Conselho Nacional de Assistência Social, Resoluções no 3, 23 de janeiro de 2009. [Acesso em 15 nov 2015]. Disponível em:

http://www.mds.gov.br/cnas/Entidades\%20Certificadas/deliberacoes/arquivos/2009/resoluc ao-003-23-01-2009.pdf

23 Brasil. Ministério do Desenvolvimento Social e Combate à Fome. Conselho Nacional de Assistência Social, Resoluções no 7, 3 de fevereiro de 2009. [Acesso em 15 nov 2015]. Disponível em: http://aspta.org.br/wp-content/uploads/2011/01/Deferimento-Certificado-deEntidade-Beneficiente-2008.pdf

24 Brasil. Ministério do Desenvolvimento Social e Combate à Fome. Conselho Nacional de Assistência Social, Resoluções no 8, 4 de fevereiro de 2009. [Acesso em 15 nov 2015]. Disponível em:

http://www.mds.gov.br/cnas/Entidades\%20Certificadas/deliberacoes/arquivos/2009/resoluc ao-008-04-02-2009.pdf

25 Brasil. Superior Tribunal Federal. Arguição de Descumprimento de Preceito Fundamento, № 265. [Internet]. Brasília, 17 mar 2010. [Acesso em 1 nov 2015]. Disponível em: http://www.stf.jus.br/portal/processo/verProcessoAndamento.asp?incidente $=4292187$.

26 Brasil. Ministério da Previdência Social. Consultoria Jurídica. Nota DECOR/CGU/AGU № 180/2009-JGAS [Internet]. Brasília, 2014. [Acesso em 22 nov 2015]. Disponível em: http://www.agu.gov.br/page/download/index/id/25730728 
27 Brasil. Poder Legislativo. Lei no 12.453, de 21 de julho de 2011 [Acesso em 10 nov 2015]. Disponível em: http://www.planalto.gov.br/ccivil 03/ Ato20112014/2011/Lei/L12453.htm\#art9

Recebido em: 5/1/2016

Reapresentado em: 5/12/2016

Aprovado em: 9/12/2016

\section{Como citar este artigo:}

Júnior Yegor M, Alves SMC, Almeida LL. A Certificação de Entidades de Assistência Social na área da saúde: alterações normativas 2008-2016. Revista Cadernos Ibero-Americanos de Direito Sanitário. 2016 dez., 5 supl. 1:39-60. 